\begin{abstract}
Maja Vasiljević
Faculty of Philosophy, University of Belgrade Čika Ljubina 18-20, 11000 Belgrade, Serbia elmaja2112@gmail.com Vladimir Abramović Faculty of Philosophy, University of Belgrade Čika Ljubina 18-20, 11000 Belgrade, Serbia vabramovic@gmail.com
\end{abstract}

\title{
BIBLIOGRAPHY ON AND ABOUT EUGENICS IN THE KINGDOM OF SERBS, CROATS AND SLOVENES/YUGOSLAVIA*
}

Арсић, Горан. “Еугенетика и/ли благородност истине која ослобађа, Зений: маїазин за книжевности, уметиности и философију 2/5 (2007), 111-118

Bartulin, N. “The ideal Nordic-Dinaric racial type: Racial anthropology in the Independent State of Croatia," Review of Croatian History 5 (2009), 189-219.

Balabanić, J. “Darvinizam u Hrvatskoj između znanosti i ideologije," Nova prisutnost 7(2009), 373-406.

Bazala, Vladimir. “Negativna, pozitivna i korektivna eugenika," Pravda (26-27. oktobar 1935)

Дегриз, Лукас. [прев. Марко Аврамеску] “Правда, еугеника и постчовечанство,"

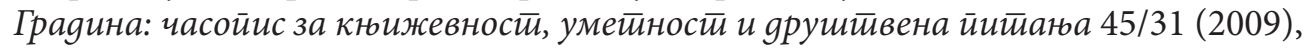
93-101

Dugac, Željko. Protiv bolesti i neznanja: Rockefellerova fondacija u međuratnoj Jugoslaviji. Zagreb. 2005

\footnotetext{
* This paper has been written as a part of national project "Modernization of Western Balkans" (No. 177009), funded by The Ministry of Education, Science and Technology of Republic of Serbia.
} 
Dugac, Željko. "Andrija Štampar i javno-zdravstvena politika Kraljevine Srba Hrvata i Slovenaca - Jugoslavije," u Balen I, Kovačić L, ur., Andrija Štampar: Radovi sa znanstvenih skupova Dani Andrije Štampara u Slavonskom Brodu. Slavonski Brod: Opća bolnica Dr. Josip Benčević; 2009, 63-76.

Dugac, Željko, Kako biti čist i zdrav. Zdravstveno prosvjećivanje u međuratnoj $\mathrm{Hr}$ vatskoj. Zagreb 2010.

Dugac, Željko. "Like Yeast in Fermentation: Public Health in Interwar Yugoslavia," u Promitzer, Christian, Sevastē Troumpeta, Marius Turda, ur., Health, hygiene, and eugenics in southeastern Europe to 1945. Vol. 2. Central European University Press, 2011

Дворниковић, Владимир. Каракиетеролоіија Јуіословена. Београд, 1939.

Evgenika: priloga Zdravniškega vestnika. Leto 1, št. 1 (feb. 1935) - leto 4, št. 4/5 (dec.1938). Golnik: Slovensko zdravniško društvo, 1935-1938.

Falina, Maria. "Between 'Clerical Fascism' and Political Orthodoxy: Orthodox Christianity and Nationalism in Interwar Serbia," u Matthew Feldman, Marius Turda, ur., Clerical Fascism in Interwar Europe. London: Routledge, 2008, 35-46.

Fatović-Ferenčić, Stella. "Society as an Organism: Metaphor as Departure Point of Andrija Štampar's Health Ideology," Croatian Medical Journal 49 (2008), 709-719

Fatović-Ferenčić, Stella. "Znanost u službi ideologija: Kako je eugenika izmanipulirala zbilju," u Fatović-Ferenčić S, Tucak A, ur. Medicinska etika. Zagreb: Medicinska naklada, 2011, 41-43.

Gjukić, M. "Vrsta, rasa i konstitucija," Liječnički vjesnik 64 (1942) 375-379

Gjukić, M. "Nekoliko riječi o principima eugenike (rasne higijene) i njenoj današnjoj primjeni," Liječnički vjesnik 64 (1942), 413-417

Gjukić, M. "Praktična upotreba nauke o baštinjenju kod ljudi," Liječnički vjesnik 65 (1943), 121-130

Gosti, B. “Duševna higijena i rasni problem," Ars therapeutica 10 (1937), 223-232.

Gosti, B. "Rasni problemi u svetlosti duševne higijene," Pravda (14-15. februar 1935)

Glumbić, Nenad. "Etičke dileme u prevenciji i tretmanu ometenosti," u Nove tendencije u specijalnoj edukaciji i rehabilitaciji, urednik Dobrivoje Radovanović, 187-212. Beograd: Fakultet za specijalnu edukaciju i rehabilitaciju, Centar za izdavačku delatnost (CID), 2007.

Grmek, M. D. urednik. Serving the Cause of Public Health. Selected Papers of Andrija Štampar. Zagreb: Andrija Štampar School of Public Health, 1966.

Hrenčević, Juraj. “Eugenika i pomlađivanje," Ars therapeutica 10 (1937)

Ilić, Petar M. “O preporoñaju današnjeg čoveka," Glas Matice srpske jul (1938)

Иванић, Стеван 3. „Кућа на селу,“ Гласник ценнирралної Хиїијенскої завоgа 17/4 (1934), 145-154 
Ivanić, Stevan. "Dr. G. Banu L’hygiène de la race," Glasnik Centralnog higijenskog zavoda, Beograd 1-2 (1939)

Ivanov, Damyan. "Shto e evgenika," Narod i potomstvo 1 (1935), 1.

"Izveštaj o radu Centralnog higijenskog zavoda u Beogradu 1932 god. (direktor dr. Stev. Z. Ivanić)," Socijalno-medicinski pregled, mart-jun (1933)

"Izveštaj o radu Centralnog higijenskog zavoda u Beogradu 1933 godine," Socijalnomedicinski pregled maj-avgust (1934)

"Izveštaj o radu Centralnog higijenskog zavoda u Beogradu 1934 godine," Socijalnomedicinski pregled januar-april (1935)

Jelovšek, Vladimir. “Rasna higijena," Liječnički vjesnik - Staleški 46 (1924)

Јевремовић, Милан П. Размиштьағь о иррейорођају gанашъеї човека, Београд. 1937.

Јојкић, Младен. Саgани Србин. Покушај физиолошко-йайолошке стиудије о срӣском нароgу. Суботица: Штампарија Винка Блесића, 1895.Kohout, В. “Higijena društva (eugenija)," Liječnički vjesnik 35(1913),546-53, 604-10

Kostić, Aleksandar Đ. “Glavna načela rasne higijene,” Zdravlje (januar 1933)

Kostić, Aleksandar Đ. "O jednom zanemarenom putu da se dođe do zdravog naroda," Zdravlje (maj 1933)

Kostić, Aleksandar. "Kako će u Nemačkoj nasledno obolele operisati da bi postali neplodni," Politika (12. novembar 1933)

Kostić, Aleksandar. "Moralna vrednost regulisanja rađanja," Politika (13. novembar 1938) Krautzer, Franjo. “Znanstvena podloga eugenike,” Obnovljeni život 18/2 (1937), 59-72

Krautzer, Franjo. "Mendelizam, eugenika i ljudski rod," Obnovljeni život 18/4 (1937), 154-163.

Krulj U. Važnost higijene za državu i naciju. Sarajevo: Zdravstveni odsek za Bosnu i Hercegovinu, 1920.

Krulj U., Politika i rasa - Rasni nacionalizam. Sarajevo, 1925.

Kuhar, Martin, Fatović-Ferenčić, Stella. "Prostitutes and criminals: beginnings of eugenics in Croatia in the works of Fran Gundrum from Oriovac (1856-1919)," Croat Medical Journal 53(2012), 185-97.

Kuhar, Martin. Eugenika u hrvatskoj medicini i njezin utjecaj na javnost u razdoblju od 1859. do 1945. doktorska disertacija, Sveučilište u Zagrebu, 2015

Маклецов, Александар. “Борба за оплемењавање расе," Лейойис Майице срӣске CIII 321/2 (авг. 1929), 287-291

Maleš, Branimir. Antropološka ispitivanja. Prilog ispitivanju telesnih osobina crnogorskih i susednih plemena. Beograd. 1932.

Maleš, Branimir. „Rase i krvne grupe,“ Ideje 3 (1934) 
Малеш, Бранимир. "Неколико напомена о динарској раси," Социјалномедицински йреїлеg 7/2 (1936), 1-7

Maleš, Branimir. „Narodnost i rase,“ Ideje 10 (1935)

Малеш, Бранимир. О тьуским расама. Београд, 1936.

Maleš, Branimir. „Problem našeg nacionalizma: U čuvanju rasnih odlika naših je Spas, “Ideje 19 (1935)

Maleš, Branimir. "Rase kojima pripadaju Srbi i Hrvati," Socijalno-medicinski pregled (oktobar-decembar 1937)

Малеш, Бранимир. „Жута опасност као демографска појава,“ XX век 2 (феб. 1938)

Maleš, Branimir. “Definicija rase," XX vek (sept. 1938)

Малеш, Бранимир. „Расно порекло Светог Саве,“ ХX век (1939)

Maleš, Branimir. “Jevreji kao rasa," Vreme (23.10.1940)

Malović, Ilija. "Eugenika kao ideološki sastojak fašizma u Srbiji 1930-ih godina XX veka," Sociologija: časopis za sociologiju, socijalnu psihologiju i socijalnu antropologiju: organ Jugoslovenskog sociološkog društva i Sociološkog odeljenja Instituta društvenih nauka 50/1 (2008), 79-96

Марковић, Лаза. Расна хиіијјена коg нас. Нови Сад: Здравствени одсек за Банат, Бачку и Барању (s. a.)

Марковић, Лаза. Заgаци народне уйраве за унайређене расне хиіијене и евїенике. Нови Сад: Штампарија Супек и Јовановића, (s.a.)

Марковић, Лаза. Жениgба и уgаgба или како ће нароg gоћи gо gобра йоgмлайка. Нови Сад: Матица српска, 1913.

Marković, Laza. "Potreba rasnohigijenske reforme braka," Glasnik Ministarstva narodnog zdravlja 1 (1919-1920), 74-77, 110-115, 153-155

Marković, Laza. "Rasna higijena - nacrt zakona o braku," Glasnik Ministarstva narodnog zdravlja 1 (1919-1920), 126-30.

Марковић, Лаза. Женияба и уgаgба или како ће нароg gоћи gо gобра йоgмлайка. Нови Сад: Државна школа за здравствено просвећивање, 1922.

Марковић, Лаза. Зашӣо Срби ирре времена умиру? Загреб: Привредникова књижара и штампарија, Д. Д., 1914.

Mattauschek, Emil. "Einiges über die Degeneration des bosnisch-herzegowinischen Volkes," Jahrbücher für Psychiatrie und Neurologie 29 (1908), 134-48

Mazover, Mark. [prev. Adriana Zaharijević] "Zdrava tela, bolesna tela," Treći program 139/140 (2008), 434-460

Milosavljević, Olivera. "Eugenika," u Savremenici fašizma: 2 Jugoslavija u okruženju 1933-1941. Beograd: Helsinški odbor za ljudska prava, 2010, 84-102 
Mitrović, Veselin. “Liberalna eugenika: ideologija poboljšanja?” Antropologija: časopis Centra za etnološka i antropološka istraživanja (CEAI) Filozofskog fakulteta Univerziteta u Beogradu 12/2 (2012), 63-79

Molnar, Aleksandar. „Houston Stewart Chamberlain: Počeci rasnog svetonazora,“ Theoria: časopis Filozofskog društva Srbije 39/3 (1996), 41-105

Obuljen, Miho. "Dužnost i potreba izučavanja rasnog problema," Narodna odbrana (28. jul 1935)

Obuljen, Miho. "Dužnost i potreba izučavanja rasnog problema”, Narodna odbrana (28. jul-4. avgust 1935)

Obuljen, Miho. "Josif Artur grof Gobino," Narodna odbrana (6. septembar 1935)

Obuljen, Miho. "Nauka o ljudskim rasama, nacionalna potreba i dužnost," Otadžbina (28. januar 1937)

“Otsek za rasnu higijenu," Zdravlje (jun-jul 1933)

Pavlović E. "Dr. Nikola Sučić - jedan od prvih hrvatskih seksologa," u Škrobonja A, ur., Rijeka i Riječani u medicinskoj povjesnici 2000.-2009. Rijeka, 2011.

Pirc, Bojan. Opadanje stanovništva u Slavoniji. Beograd: Štamparija Centralnog higijenskog zavoda, 1931.

Pirc, Bojan. “Zašto nestaju narodi," Zdravlje 3-4 (1937)

"Poboljšanje kvaliteta naše rase nacionalni problem," Vreme (12. septembar 1933)

Popović, J. "Očne bolesti sa gledišta rasne higijene," Glasnik Ministarstva narodnog zdravlja 5 (1924), 200-209

Popović, L. "K nacrtu novog sanitetskog zakona: Eugenika," Liječnički vjesnik - Staleški 43 (1921)

Popović L. “Eugenika," Nova Evropa 1 (1920), 243-24

"Rasno biološko odabiranje," Otadžbina (18. mart 1934)

Савићевић, Милорад. Ко се сме женийи? Београд: Државна штампарија Краљевине Србије, 1909.

Савићевић, Милорад. Ко се сме женити?? Београд: Издање Свесловенске књижарнице, 1913.

Станковић, Синиша. Живойни ӣрост̄ор. Београд, 1940.

Станојевић, Владимир С. Буквар војничкої зgравља. Београд: Министарство војно и морнарице, Државна штампарија Краљевине Срба, Хрвата и Словенаца, 1920.

Станојевић, Владимир С. Буквар војничког̄ зgравља. Подсетник за војнике и подофицире у кадру и резерви. Београд: Здравље, 1922.

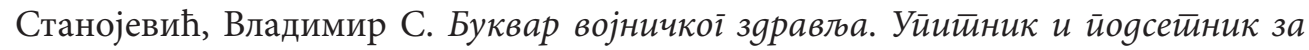
војнике и ӣogобицире у каgру и у резерви са сликама. Београд, 1923. 
Stanojević, Vladimir S. Bukvar vojničkog zdravlja. Upitnik $i$ podsetnik za vojnike $i$ podoficire u kadru i u rezervi sa slikama. Beograd: Zdravlje, 1925.

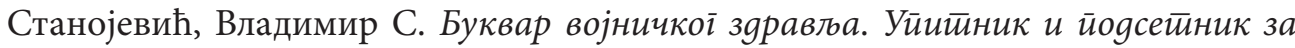
војнике и йоgофищире у каgру и у резерви. Са сликама. Београд: Здравље, 1926.

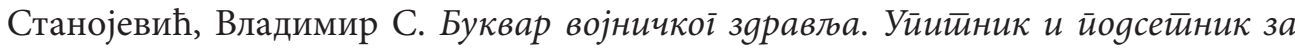
војнике и йоgофицире у каgру и у резерви са сликама. Београд: Здравље, 1927.

Stanojević, Vladimir S. Bukvar vojničkog zdravlja. Znanja i pouke o zdravlju za vojnike i podoficire u kadru i u rezervi sa slikama. Beograd, 1927.

Станојевић, Владимир С. Еуїеника: Хиїијена човечјеі зачећа и ӣроблем наслеђа. Београд: Министарство народног здравља, 1920.

Stanojević S. "Eugenika i rasno-higijenski problem," Glasnik Ministarstva narodnog zdravlja 1(1919-1920), 20-26

Stefanović, Svetislav. „O krvnim grupama i rasnom problemu, “ Ideje 6 (1934)

Stefanović, Svetislav. „Odgovor na neozbiljna raspravljanja rasnog pitanja u nas: Rasa i kultura, "Ideje 22 (1935)

Stefanović, Svetislav. “Rasna higijena, abortus i mere zaštite," Evgenika 1/5 (1935)

Stefanović, Svetislav. “Rasa i kultura (1935)," u: Starim ili novim putevima, Novi Sad, 2006, 321-322.

Stefanović, Svetislav. „Socijalne tendencije rasizma: Rasizam i ekonomska struktura Društva, “Ideje 26 (1935)

Stefanovic, Svetislav. “Za zdravstveno podizanje sela," Jugoslovensko lekarsko društvo (1934)

Sučić, Nikola. Spolne bolesti: spolni život i higijena braka. Zagreb: Tisak jugoslovenske štampe, 1937.

Sučić, Nikola. Bolesti živaca i duše: Psihopatije, psihoneuroze i psihoze - Tjelesna gradja, temperamenat $i$ karakter. Zagreb: Tisak jugoslovenske štampe, 1933.

Sučić, Nikola. Na izvoru života. Zagreb: Tisak hrvatske državne tiskare, 1943.

Sučić, Nikola. "Rase i rasno pitanje”, Seljačke novosti 11/51-52 (1935), 7-8

Sučić, Nikola. “Za zdravo potomstvo," Seljačke novosti 12/2 (1936), 4.

Sučić, Nikola. "Nasljedstvo roda i bolesti koje se naslijedjuju," Seljačke novosti 16/5152 (1940), 12-13

Štampar, Andrija. "Socijalna higijena," Slobodna riječ 9 (1910), 5

Štampar, Andrija. "Kako ćemo očuvati narodno zdravlje?," Hrvatska njiva 2 (1918), 481-483

Štampar, Andrija. “O zdravstvenoj politici,” Jugoslavenska njiva 29-31 (1919), 1-29

Štampar, Andrija. "Rasna higijena: Preporođaj," Glasnik Ministarstva narodnog zdravlja 1 (1919- 1920) 
Štampar, Andrija. "O socijalnoj medicine," Glasnik Ministarstva narodnog zdravlja 4 (1923), $1-12$

Štampar, Andrija. "Pet godina rada na higijeni," Glasnik Ministarstva narodnog zdravlja 6 (1925), 289-91

Štampar, Andrija ur. Socijalna medicina. Zagreb: Institut za socijalnu medicine, 1925.

Štampar, Andrija. Higijena i socijalna medicina. Zagreb: Narodne novine, 1940.

Thaller, Lujo. "Eugenika," Narodna zaštita 2 (1918)

Thaller, Lujo. "Eugenika i ženidba: Opaske raznim prijedlozima o zabrani braka," Glasnik Ministarstva narodnog zdravlja 1(1919-1920), 508-513.

Tomašić, D. "Eugenika i rasne teorije," Savremeni hrvatski medicinar 1 (1937), 74-7

Tomašić, D. Kritika rasne interpretacije političke historije Hrvata i Srba. Ljubljana: Jugoslovanska tiskara, 1937

Tomašić, D. "Psihička i politička pozadina rasnih teorija," Nova riječ 2/11 (1937), 4

Tomašić, D. "Rasno tumačenje društva," Mjesečnik Pravničkoga društva u Zagrebu 66 (1940), 19-28

Trifunović, Mih. Principi vonenja, u prirodi i ljudskom društvu. Pančevo, 1937.

"U Beogradu se živo radi na pripremanju velike higijenske izložbe," Pravda (27. mart 1933)

Valensin, Albert. "Eugenika i moral," Obnovljeni život 13/6. (1932), 241-253

Vasiljević, Milosav. Sociološki trebnik. Beograd, 1940.

Vuletić, A. "Položaj liječnika i rasna higijena," Ars therapeutica 7 (1934), 149-156.

Yeomans, Rory. 'Of 'Yugoslav Barbarians' and Croatian Gentlemen Scholars: Nationalist Ideology and Racial Anthropology in InterwarYugoslavia," u Marius Turda, Paul J. Weindling, ur., Blood and Homeland: Eugenics and Racial Nationalism in Central and Southeast Europe, 1900-1940. Budapest: Central European University Press, 2007, 83-122.

Yeomans Rory. "Fighting the white plague: Demography and abortion in the Independent State of Croatia," u Promitzer C, Trubeta S, Turda M, ur., Health, hygiene and eugenics in Southeastern Europe to 1945. Budapest \& New York: CEU Press; 2011, 385- 426.

Зоргнер, Стефан Лоренц. [прев. Бранка Јовановић] “Фасете еугенике,” Зений:

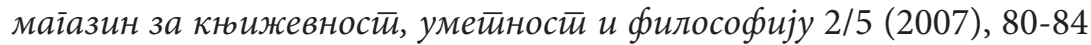

Zakonska odredba o zabrani i kažnjavanju uzrokovanog pometnuća i o prekidanju trudnoće. Narodne novine 1941, br. 49.

Zakon o suzbijanju polnih bolesti. Narodne novine - Službeni list 1934, br. 131.

Zarnik, B. “Eugeničke smjernice," Priroda 22 (1932), 152-153 
Zarnik, B. “Eugenika i država," Narodne novine 98/80 (1932), 4

Zarnik, B. “Poziv na osnivanje Antropološko-eugeničkog društva," Priroda 24 (1934), 61-62

Zarnik, B. "Da li su za naš narod potrebne eugeničke mjere?," Savremeni hrvatski medicinar 1 (1937), 37-42

Zarnik, B. “O rasnom sastavu evropskog pučanstva," Hrvatsko kolo 8 (1927), 40-80

Zarnik, B. "Krv i rasa," Priroda 20 (1930), 1-14

Zarnik, B. “Rasa i duševna produktivnost," Priroda 21 (1931), 129-140

Živković, Andrija. Eugenika i moral. Zagreb: Hrvatska bogoslovska akademija, 1933.

Živković, Andrija. "Iz povijesti eugenike," Bogoslovska smotra 21/2 (1933), 160-168

Živković, Ljubomir. Ljudsko društvo i rasna teorija. Zagreb, 1937.

Živković Lj. "Eugenika i ljudsko društvo," Savremeni hrvatski medicinar 1 (1937), $117-126$

Živković, Lj. “Rasna nauka i rasna ideologija," Znanost i život 1 (1937), 165-172

Županić, Niko. Evgenika dr. Ivana Tavčarja. Ljubljana, 1921.

Županić, Niko. O rasni estetiki ljudstva pri Jugoslovenah. Ljubljana: Etnografski muzej i Učiteljska tiskarna, 1935. 